\title{
1 Spanish biofuels heating value estimation based on structural analysis
}

2 Ana Álvarez, Consuelo Pizarro*, Roberto García, Julio L. Bueno

3 Department of Chemical and Environmental Engineering, Faculty of Chemistry,

4 University of Oviedo. Ave. Julián Clavería, 33006, Oviedo, Spain

$5 \quad$ *corresponding author

6 Telephone: +34 985103438

$7 \quad$ Fax: +34 985103434

8 e-mail: pizarroconsuelo@uniovi.es

\section{Abstract}

11 The importance of waste biomass as an energy source is likely to increase

12 during the coming years as a result of European energy policy objectives, and

13 because of the wide range of possibilities that it offers: it is a cheap fuel, widespread, and available in large quantities. In addition to crops and forestry operations, the Spanish fruit, olive and wine industries generate large amounts of currently undervalued solid wastes such as stones, branches, pulps or

17 pomaces. The use of these by-products offers environmental benefits like removing waste and preventing fires at the same time as providing an energy yield. A proper energy valorization will require a complete physicochemical characterization. In this article, a structural and thermal characterization is developed from twenty samples from the olive and wine industries, as well as from forest and agro wastes. In addition, predictive equations are proposed to determine higher heating value (HHV) from chemical composition. For this 
purpose, the chemical extraction method (also called the 'classic' method) was used, and results were obtained in accordance with the data shown in the bibliography. Two predictive equations were developed: one based on lignin and hemicellulose content, and the other based on lignin quantity. Both present an absolute average error (AAE) of $0.87 \%$ and $1.13 \%$, respectively.

Keywords: Biomass, high heating value, structural analysis, chemical composition

\section{Introduction}

During recent years, waste biomass has gained in importance as an energy feedstock due to requirements for developing various renewable energy sources to reach European goals for the years 2020 (the "three 20s" target) and 2050.

Among complementary energy resources, biomass offers great possibilities, including those involving direct (combustion) procedures and indirect (extractive or transformative) procedures of reuse, recovery and revaluation (Barbanti et al., 2014). Since biomass as waste is cheap and available nearly everywhere (Masnadi et al., 2014), and is also responsible for lower emissions of environmentally detrimental gases like sulphur dioxide $\left(\mathrm{SO}_{2}\right)$ and nitrogen oxides $\left(\mathrm{NO}_{\mathrm{x}}\right)$, the combustion of biomass also plays a positive role in reducing global acid rain formation (Zhang et al., 2010). In addition, biomass contributes approximately $14 \%$ of worldwide energy consumption (Demirbas and Demirbas, 2007), meaning $63 \%$ of all renewable energy sources (García-Maraver et al., 
47 2012). The work of (Krzyżaniak et al., 2014 and 2015 in press; Salaheldeen et al., 2014), are worthy of mention as recent contributions. Woody crops management, like orchards, olive groves or vineyards, generate huge amounts of waste (Godin et al., 2013).

To achieve an efficient reuse of residual vegetable biomass, the availability of the raw matter (quality, quantity, location of origin) must be reconciled with the characteristics of the chosen or available technical alternatives (fundamentals of procedures, optimal design capacity and location of the consumers of commercial energy). The technical and economic success of most of the options is thus strongly associated with geography, climate and customer

57 requirements.

In Spain, the biggest potential biomass source belongs to Andalucía and

Castilla-La Mancha, which together provide nearly $50 \%$ of all woody crop wastes (Rosúa and Pasadas, 2012). It should be noted that, due to high production, olive and wine industrial wastes are plentiful in Spain, but not sufficiently valued. These two industries produce a large quantity of several types of biomasses with different properties. Spain's Surfaces and Crop Yields Inquiry (ESYRCE) shows an overall vineyard-crop cultivation area of 963,644 hectares, while the olive growing area amounts to $2,593,523$ hectares, meaning $5.7 \%$ and a $15.1 \%$, respectively, of overall cultivated surface area in Spain.

The main organic wastes obtained from the olive industry are olive pomace, extracted olive pomace (coming from oil mills), olive vegetable water (also 
"alperujo") and, in lower quantities, olive stones. Figures $1 \mathrm{a}$ and $1 \mathrm{~b}$ show a diagram of olive oil production using the three existing procedures and an extractive plant flow chart.

The main organic wastes from the wine industry are pomace (pressed grape waste), lees (fermentation and maturing precipitates), wine wash water (vinasse), and the grape stalks that are separated in the destemmer. Figure 2 shows a white wine production chart, indicating wastes obtained in each phase of production. Red wine production is slightly different, but the same types of wastes are obtained.

Figures $1 \mathrm{a}, 1 \mathrm{~b}$ and 2 illustrate olive and wine production wastes organized according to colour. Thus, the green boxes are solid wastes, which are the subject of interest in this work, while the liquids, which are not studied here, appear in yellow. Finally, end or tail products for each process are marked in blue, and sub-products and other wastes are marked in grey.

In addition to the woody crops, there are other biomass sources like the harvesting of shrubland areas or of whole trees not necessarily coming from agro-crops. The thinning out of wooded areas and the proper treatment of shrubs is a useful tool for preventing disease while sustainably exploiting Spain's woody regions. Olive groves, vineyards and orchards require regular pruning, which generates a huge amount of biomass available for energy use (Spinelli and Picchi, 2010).

On the other hand, extensive neglected scrubland zones are an undesirable fuel source and the main spreader of forest fires in Spain, and they represent a 
93 significant environmental impact because of adding to the greenhouse effect.

94 The valorization of these wastes could be an incentive for environmental clean-

95 up, considering that forestry biomass reaches $18,715,359$ tonnes per year, while the whole biomass potential in Spain alone reaches $88,677,193$ tonnes per year, as shown in Table 1.

In fact, not all of these waste materials are usually properly managed. For example, prunings are commonly burned in the same place where they are gathered (Velázquez-Martí et al., 2011). The energy use of these wastes not only contributes to sustainable energy production, but also improves the management of waste materials in situ.

Taking into account the lack of accurate biomass standardization, particularly in terms of physicochemical, process and environmental indicators, the evaluation and selection of raw materials for obtaining better process efficiencies presents many difficulties. Therefore, a proper characterization is required for the adequate use the wastes previously described.

The properties of commercial fuel are usually well known. Nevertheless, some waste-biomasses, like the ones studied in this article, are not fully standardized and do not follow any specific, existing normative (that for pellets, for example), so it becomes necessary to study their characterization in depth. This research group has previously developed studies on the proximate and ultimate analysis of biomass fuels (García et al., 2014a, 2014b). A chemical composition study of those materials is thus required in order to fully complete this work. 
115 The main structural components of biomass are cellulose, hemicellulose and

116 lignin. Cellulose appears in the largest quantities in lignocellulosic biomass,

117 which is a linear polymer formed by B-glucose units joined together by $B-1,4-$

118 glucosidic bonds. In addition, as a whole, it possesses a fibrous structure in

119 which hydrogen-bridge bonds between hydroxyl groups of alternate glucose

120 chains are formed, making it tough and insoluble to water (Smook, 2002).

121 Hemicelluloses, as cellulose, are polymers made of pentoses, hexoses and

122 uronic acid units. They are smaller than cellulose and, also being amorphous

123 polysaccharides, each unit generally contains more than one kind of sugar

124 (Carrier et al., 2011).

Lignin is a 3D polymer formed by three units of phenylpropane (conipheryl, sinapyl and coumaryl alcohols). Lignin possesses a huge variety of functional groups and 10 different bond types (Tejado et al., 2007).

Figure 3 shows the 3D order of the main biomass chemical components as well as the proportion in which they usually appear. The images were obtained using a Scanning Electron Microscope (SEM), at a magnification of 110x, 250x and 130x for lignin, cellulose and hemicellulose, respectively.

In Figure 3, depicts how cellulose appears as long fibres surrounded by a net of hemicellulose, joined by hydrogen-bridge bonds. Lignin is placed as a matrix between the strings formed by the merging of cellulose and hemicellulose.

135 These fractions are joined by hydrogen-bridges and covalent bonds (benzyl esters, benzyl ethers and phenyl glycosides (Smook, 2002)). 
137 Chemical composition is closely related to the potential applications of a

material and therefore to its energy use because higher heating value (HHV) greatly depends on these compounds. This relationship can be observed by the existence of varying HHV-predictive equations based on chemical composition.

The common methods for determining Lower Heating Values (LHV, defined as excluding heating losses through sub-products of combustion) and Higher Heating Values (HHV), may be classified into three inter-connected basic groups: theory, direct experimentation and empirical correlations. In fact, thermodynamic models based on rigorous state theories have the drastic inconvenience of needing detailed and precise analysis of all of the thousands of molecules present in such a natural product in order to reliably integrate (if previously available) a significant number of reactive internal energies or enthalpies. Experimentation must be carried out using original and sophisticated laboratory techniques or by precise, consolidated and commercially welldeveloped ones, e.g., by calorimetric bomb. Empirical estimations attempt to shortcut time-consuming experimental calculations, thus reaching the typical engineering compromise between requirements and accuracy. This question has been thoroughly discussed in some of our previous contributions (García et al., 2014a, 2014b).

The purpose of these last methods, particularly useful in a practical context, is to avoid slow and cumbersome procedures correlating HHV and LHV with less onerous available data (i.e., structural analysis is preferable to elemental analysis) while maintaining reliability within acceptable limits. 
160 This work proposes several equations, based on experimentally obtained data, 161 which enlarge the inventory of equations previously proposed by other authors, 162 and which is summarized in Table 2.

163 As can be seen in Table 2, equations obtained after bibliographical review can 164 be categorized for specific biomass groups (like TIL or WHI, exclusively for woody fuels) or with broad, general applicability. They can also be defined from 166 just one biomass fraction (like ACA or DEM01, 03 and 04) or from more than 167 one, such as J\&G, which uses all structural biomass components in their 168 proposed correlation. In addition, fractions used to calculate HHV values may be expressed on a different basis by different authors.

170 The new equations proposed here for estimating HHV are based on the chemical structural analysis of biomass samples.

\section{Samples and methods}

\subsection{Samples}

Chemical composition and HHV were determined for twenty biomass samples belonging to agro-forestry wastes and industrial wastes. For the purpose of

177 illustration, Figure 4 shows some of the analyzed samples.

178 As a pre-treatment to sort and isolate the analyzed fractions, all studied samples were grinded and milled until particle size was in the range of 250$500 \mu \mathrm{m}$ (TAPPI, 2007). 
182 Biomass chemical composition can be obtained through a chemical extraction

183 process that is summarized in Figure 5. Data for different fractions are expressed on the basis of free dry, ash and extractives. Every experimental run, except the singular extractive determinations, was performed three times to assure reproducibility according to a pre-established accuracy.

\subsubsection{Sample preparation}

Before quantifying different biomass fractions, it was necessary to homogenize sample size distribution. Once this was achieved, samples were subjected to a two-stage extraction process to eliminate a group of substances known as "extractives" that may interfere with a rigorous characterization. The first of these stages consisted of an acetone treatment in a Soxhlet extractor lasting 78 hours to get rid of resins, waxes, sterols, fats and fatty acids. The second phase was carried out with boiling water for 1 hour: tannins, gums, sugars and coloured matter were removed. Once both phases were completed, the refined biomass was air-dried to reduce its moisture content to below $15 \%$.

This quantity was obtained from an extractive-free biomass using an acetic acid and sodium chloride treatment, according to the ASTM D-1104 standard (Test for Holocellulose in Wood) (ASTM International, 1978). 
202 Cellulose quantity was determined from the holocellulose fraction obtained previously. This procedure consisted of a sodium hydroxide treatment according to the TAPPI T 212 standard (TAPPI, 2002). Hemicellulose content can be derived from the difference between holocellulose and cellulose quantities.

Lignin quantification was determined according to the NREL/TP-510-42618 standard (A. Sluiter et al., 2008), which consists of a two-stage acid hydrolysis, with the first step using concentrated sulphur acid and the second stage with

210 the same diluted agent at high pressure.

\subsubsection{Ash fraction determination}

212 An ash quantification test, following the NREL/TP-510-42622 (A. Sluiter et al., 2005) standard, was carried out. This procedure consists of a thermal treatment of each fraction at $600^{\circ} \mathrm{C}$ for every previously calculated fraction.

\subsubsection{HHV determination}

216 The quantification of this energy content indicator was carried out using an IKA

217 Werke C5000 calorimetric bomb, and following the ASTM E711 (ASTM

218 International, 1987) standard. HHV data used in this article are shown in 219 Table 3. 


\section{Results and discussion}

224 3.1. Structural Analysis

225 Analysis data obtained by chemical extraction for each studied sample are 226 shown in Table 4. Contents of structural components are normalised to $100 \%$.

227 Analysed samples demonstrate a wide range of extractive matter ratios, from $0.35 \%$ for chestnut tree chips, to $67 \%$ for extracted olive pomace. The variability in structural component quantity is not as wide. As expected, values between $21 \%$ and $39 \%$ were found for lignin, but grape stalk was exceptional with a value of over $50 \%$. The range for cellulose was $27 \%$ to $60 \%$, while for hemicellulose the indices obtained were between $10.68 \%$ for olive stone and $42.79 \%$ for corncob. The exception, once again, was grape stalk, which exhibited just $2 \%$. These results were been compared with others available in the literature such as those of (Vassilev et al., 2012; Mendes et al., 2013; Prozil et al., 2012; Matos et al., 2010), and there is a notably strong agreement among them.

\subsection{HHV estimations}

The first step consisted of determining which of the parameters is the most

240 influential on an HHV estimate. Matlab's command corrcoef was used for this purpose. $\mathrm{R}$ and $\mathrm{P}$ matrixes were obtained, with $\mathrm{R}$ being a squared matrix of correlation coefficients, with as many rows and columns as compared variables.

243 The $\mathrm{P}$ matrix contains the P-values, and is the result of checking the non-

244 correlation hypothesis. The results for the tested variables are shown in 245 Table 5. 
246 According to the statistical protocol, the closer to 0 a P-value comes, the higher

247 the probability of dependence there is between the correlated variables, so the corresponding R-values can be considered significant. An examination of Table 5 shows that correlations obtained for cellulose demonstrate P-values much

250 higher than 0.05 , so the relationship between $\mathrm{HHV}$ and this parameter is meaningless. Therefore, no cellulose-based correlations have been proposed.

252 Nevertheless, the P-values obtained for lignin and hemicellulose were low, so these fractions should be considered as important in determining HHV.

After choosing the most important parameters, the Matlab command regress is used to obtain linear equations based on the selected parameters or linear combinations thereof. The correlations thus obtained were statistically checked using three criteria: absolute average error ( $\mathrm{AAE})$, average bias error ( $\mathrm{ABE})$, defined as follows: relative errors commonly used by several authors (Callejón-Ferre et al., 2014; Sheng and Azevedo, 2005) and average absolute deviation (AAD). They are

$$
\begin{aligned}
& \operatorname{AAE}(\%)=\frac{1}{n}\left[\sum 100 \frac{\left|\mathrm{HHV}_{\text {calc }}-\mathrm{HHV}_{\text {exp }}\right|}{\mathrm{HHV}_{\text {exp }}}\right] \\
& \operatorname{ABE}(\%)=\frac{1}{\mathrm{n}}\left[\sum 100 \frac{\left(\mathrm{HHV}_{\text {calc } \left.^{-}-\mathrm{HHV}_{\text {exp }}\right)}\right.}{\mathrm{HHV} \text { exp }}\right] \\
& \mathrm{AAD}=\frac{1}{\mathrm{n}}\left[\sum\left|H H V_{\text {calc }}-\mathrm{HHV}_{\text {exp }}\right|\right]
\end{aligned}
$$

Proposed equations and their error values are shown in Table 6. Based on structural analysis data, these equations show a lower value for $A A E(1.13 \%)$ 
267 compared to the AAE values of correlations based on proximate or elemental 268 analysis data (5\% to 7\%) proposed by the authors (García et al., 2014a, 269 2014b).

270 In Figure 6, the relationship between the predicted values (X-axis) and those

271 obtained experimentally (Y-axis) using data from the bibliography (Telmo and 272 Lousada, 2011; Demirbaş, 2001) are shown in order to validate the equations 273 proposed in this article.

274 As can be seen in Figure 6, all of the data are within a range of $13 \%$ of error 275 with respect to the experimental values.

\section{Conclusions}

278 Chemical analysis confirmed that the main component of lignocellulosic

279 biomass is cellulose (27\% to $60 \%)$, followed by lignin (21\% to $39 \%)$ and 280 hemicellulose (10\% to $43 \%)$.

281 Results obtained and shown in this article are in good agreement with those 282 obtained by other authors.

283 Higher Heating Value is related to the content of biomass structural compounds, 284 mainly lignin. Existing equations for predicting HHV are focused on specific biomass groups, while the ones proposed in this work have a general character. 
286 The equations presented in this work depend on structural biomass

287 components, predicting HHV values with an average absolute error (AAE) of 288 less than $1.13 \%$.

\section{Acknowledgements}

PSE-ARFRISOL, Ref. PS-120000-2005-1, is a science and technology project

292 qualified as strategic by the 2004-07 Spanish National Plan of Research,

293 Development and Diffusion, co-financed by the European Regional

294 Development Funds and the Spanish Science and Education Ministry. We here acknowledge all members of the PSE-ARFRISOL partnership for their cooperation.

297 We would also like to thank a number of companies, including Acciona,

298 CarsanBio, Viñadecanes Vinos, Cooperativa Agrícola de Cangas del Narcea, 299 Vino de la Tierra de Cangas and García Munté Energía for their assistance in 300 supplying most of the samples necessary for studying the different biomasses mentioned here.

A. Álvarez acknowledges receipt of a graduate fellowship from the Severo

303 Ochoa Program (Principado de Asturias, Spain).

304 This article is also greatly indebted to MINECO for the economic support given 305 to the TRIBIONOR project (CTQ2013-45155-R), which makes the continuation 306 of research in this field possible. 
Acar, S., Ayanoglu, A., 2012. Determination of Higher Heating Values (HHVs) of Biomass Fuels. Energy Educ. Sci. Technol. Part -Energy Sci. Res. 28, 749-758.

A. Sluiter, B. Hames, R. Ruiz, C. Scarlata, J. Sluiter, D. Templeton, 2005. Determination of Ash in Biomass.

A. Sluiter, B. Hames, R. Ruiz, C. Scarlata, J. Sluiter, D. Templeton, D. Crocker, 2008. Determination of Structural Carbohydrates and Lignin in Biomass (2012 Version).

ASTM International, 1987. ASTM E711 Standard Test Method for Gross Calorific Value of Refuse-Derived Fuel by the Bomb Calorimeter (WITHDRAWN 2004).

ASTM International, 1978. ASTM D1104-56(1978). Method of Test for Holocellulose in Wood (withdrawn 1985).

Barbanti, L., Di Girolamo, G., Grigatti, M., Bertin, L., Ciavatta, C., 2014. Anaerobic Digestion of Annual and Multi-Annual Biomass Crops. Ind. Crops Prod. 56, 137-144. doi:10.1016/j.indcrop.2014.03.002

Callejón-Ferre, A.J., Carreño-Sánchez, J., Suárez-Medina, F.J., Pérez-Alonso, J., Velázquez-Martí, B., 2014. Prediction Models for Higher Heating Value Based on the Structural Analysis of the Biomass of Plant Remains from the Greenhouses of Almería (Spain). Fuel 116, 377-387. doi:10.1016/j.fuel.2013.08.023 
Carrier, M., Loppinet-Serani, A., Denux, D., Lasnier, J.-M., Ham-Pichavant, F., Cansell, F., Aymonier, C., 2011. Thermogravimetric Analysis as a New Method to Determine the Lignocellulosic Composition of Biomass. Biomass Bioenergy 35, 298-307. doi:10.1016/j.biombioe.2010.08.067

Demirbas, A., 2004. Combustion Characteristics of Different Biomass Fuels. Prog. Energy Combust. Sci. 30, 219-230. doi:10.1016/j.pecs.2003.10.004

Demirbas, A., 2003. Relationships Between Heating Value and Lignin, Fixed Carbon, and Volatile Material Contents of Shells from Biomass Products. Energy Sources 25, 629-635. doi:10.1080/00908310390212336

Demirbas, A., 2002. Relationships Between Heating Value and Lignin, Moisture, Ash and Extractive Contents of Biomass Fuels. Energy Explor. Exploit. 20, 105-111. doi:10.1260/014459802760170420

Demirbaş, A., 2001. Relationships Between Lignin Contents and Heating Values of Biomass. Energy Convers. Manag. 42, 183-188. doi:10.1016/S0196-8904(00)00050-9

Demirbas, A.H., Demirbas, I., 2007. Importance of Rural Bioenergy for Developing Countries. Energy Convers. Manag. 48, 2386-2398. doi:10.1016/j.enconman.2007.03.005

García-Maraver, A., Zamorano, M., Ramos-Ridao, A., Díaz, L.F., 2012. Analysis of Olive Grove Residual Biomass Potential for Electric and Thermal 
Energy Generation in Andalusia (Spain). Renew. Sustain. Energy Rev. 16, 745-751. doi:10.1016/j.rser.2011.08.040

García, R., Pizarro, C., Lavín, A.G., Bueno, J.L., 2014a. Spanish Biofuels Heating Value Estimation. Part I: Ultimate analysis data. Fuel 117, Part B, 1130-1138. doi:10.1016/j.fuel.2013.08.048

García, R., Pizarro, C., Lavín, A.G., Bueno, J.L., 2014b. Spanish Biofuels Heating Value Estimation. Part II: Proximate analysis data. Fuel 117, Part B, 1139-1147. doi:10.1016/j.fuel.2013.08.049

Godin, B., Lamaudière, S., Agneessens, R., Schmit, T., Goffart, J.-P., Stilmant, D., Gerin, P.A., Delcarte, J., 2013. Chemical Characteristics and Biofuel Potential of Several Vegetal Biomasses Grown Under a Wide Range of Environmental Conditions. Ind. Crops Prod. 48, 1-12. doi:10.1016/j.indcrop.2013.04.007

IDAE, 2007. Plan de Energías Renovables 2011- 2020 [WWW Document]. URL http://www.idae.es/index.php/id.670/relmenu.303/mod.pags/mem.detalle (accessed 2.18.15).

Jiménez, L., González, F., 1991. Study of the Physical and Chemical Properties of Lignocellulosic Residues with a View to the Production of Fuels. Fuel 70, 947-950. doi:10.1016/0016-2361(91)90049-G

Krzyżaniak, M., Stolarski, M.J., Szczukowski, S., Tworkowski, J., Bieniek, A., Mleczek, M., 2015. Willow Biomass Obtained from Different Soils as a 
Feedstock for Energy. Ind. Crops Prod. doi:10.1016/j.indcrop.2015.06.030

Krzyżaniak, M., Stolarski, M.J., Waliszewska, B., Szczukowski, S., Tworkowski, J., Załuski, D., Śnieg, M., 2014. Willow Biomass as Feedstock for an Integrated Multi-Product Biorefinery. Ind. Crops Prod. 58, 230-237. doi:10.1016/j.indcrop.2014.04.033

Masnadi, M.S., Habibi, R., Kopyscinski, J., Hill, J.M., Bi, X., Lim, C.J., Ellis, N., Grace, J.R., 2014. Fuel Characterization and Co-pyrolysis Kinetics of Biomass and Fossil Fuels. Fuel 117, Part B, 1204-1214. doi:10.1016/j.fuel.2013.02.006

Matos, M., Barreiro, M.F., Gandini, A., 2010. Olive Stone as a Renewable Source of Biopolyols. Ind. Crops Prod. 32, 7-12. doi:10.1016/j.indcrop.2010.02.010

Mendes, J.A.S., Prozil, S.O., Evtuguin, D.V., Lopes, L.P.C., 2013. Towards Comprehensive Utilization of Winemaking Residues: Characterization of grape skins from red grape pomaces of variety Touriga Nacional. Ind. Crops Prod. 43, 25-32. doi:10.1016/j.indcrop.2012.06.047

Prozil, S.O., Evtuguin, D.V., Lopes, L.P.C., 2012. Chemical Composition of Grape Stalks of Vitis vinifera L. from Red Grape Pomaces. Ind. Crops Prod. 35, 178-184. doi:10.1016/j.indcrop.2011.06.035

Rosúa, J.M., Pasadas, M., 2012. Biomass Potential in Andalusia, from Grapevines, Olives, Fruit Trees and Poplar, for Providing Heating in 

Homes. Renew. Sustain. Energy Rev. 16, 4190-4195. doi:10.1016/j.rser.2012.02.035

Salaheldeen, M., Aroua, M.K., Mariod, A.A., Cheng, S.F., Abdelrahman, M.A., 2014. An Evaluation of Moringa peregrina Seeds as a Source for Biofuel. Ind. Crops Prod. 61, 49-61. doi:10.1016/j.indcrop.2014.06.027

Shafizadeh, F., Sarkanen, K.V., Tillman, D.A., 1976. Thermal Uses and Properties of Carbohydrates and Lignins. Academic Press, New York.

Sheng, C., Azevedo, J.L.T., 2005. Estimating the Higher Heating Value of Biomass Fuels from Basic Analysis Data. Biomass Bioenergy 28, 499507. doi:10.1016/j.biombioe.2004.11.008

Smook, G.A., 2002. Handbook for Pulp \& Paper Technologists. Angus Wilde Publications, Vancouver; Bellingham.

Spinelli, R., Picchi, G., 2010. Industrial Harvesting of Olive Tree Pruning Residue for Energy Biomass. Bioresour. Technol. 101, 730-735. doi:10.1016/j.biortech.2009.08.039

TAPPI, 2007. TAPPI T-264 cm-07. Preparation of Wood for Chemical Analysis.

TAPPI, 2002. TAPPI-T-212-om-12. One percent Sodium Hydroxide Solubility of Wood and Pulp.

Tejado, A., Peña, C., Labidi, J., Echeverria, J.M., Mondragon, I., 2007. Physicochemical Characterization of Lignins from Different Sources for use in 
Telmo, C., Lousada, J., 2011. The Explained Variation by Lignin and Extractive Contents on Higher Heating Value of Wood. Biomass Bioenergy 35, 1663-1667. doi:10.1016/j.biombioe.2010.12.038

Tillman, D.A., 2012. Wood as an Energy Resource. Elsevier.

Vassilev, S.V., Baxter, D., Andersen, L.K., Vassileva, C.G., Morgan, T.J., 2012. An Overview of the Organic and Inorganic Phase Composition of Biomass. Fuel 94, 1-33. doi:10.1016/j.fuel.2011.09.030

Velázquez-Martí, B., Fernández-González, E., López-Cortés, I., SalazarHernández, D.M., 2011. Quantification of the Residual Biomass Obtained Value of Wood. Wood Fiber Sci. 19, 446-452.

Zhang, L., Xu, C. (Charles), Champagne, P., 2010. Overview of Recent Advances in Thermo-chemical Conversion of Biomass. Energy Convers. Manag. 51, 969-982. doi:10.1016/j.enconman.2009.11.038 
433 Fig. 1a. Olive oil production flowchart: olive oil mill (hydromechanical method)

434 Fig. 1b. Olive oil production flowchart: olive pomace extractor (mass transfer 435 method)

436 Fig. 2. White wine production flowchart

$437 \quad$ Fig. 3. 3D biomass structure

$438 \quad$ Fig. 4. Pictures of the samples analysed

439 Fig. 5. Experimental procedure chart

440 Fig. 6. Predicted vs. experimental HHV from data in the bibliography 


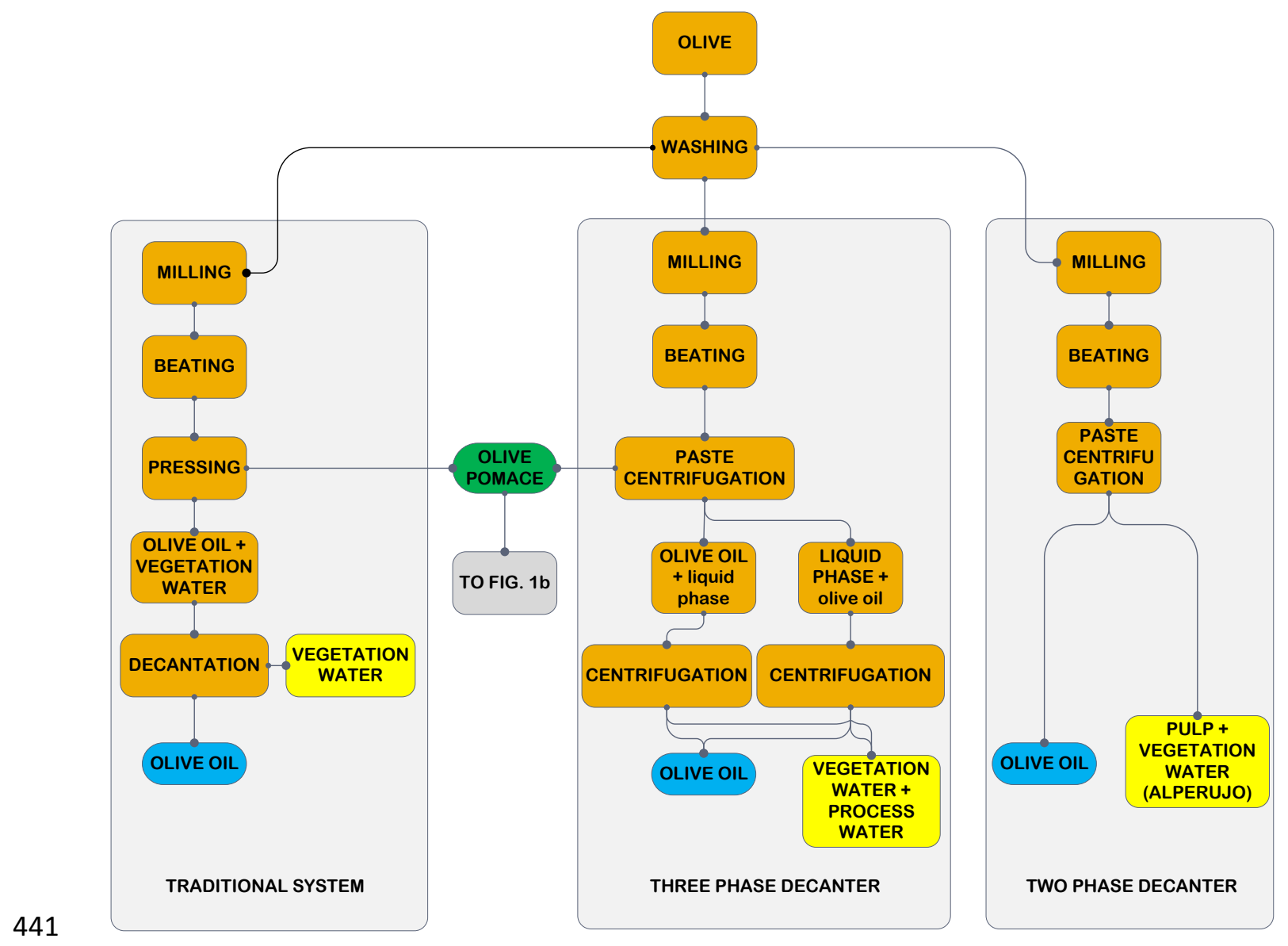

442 Fig. 1a. Olive oil production flowchart: olive oil mill (hydromechanical method). 


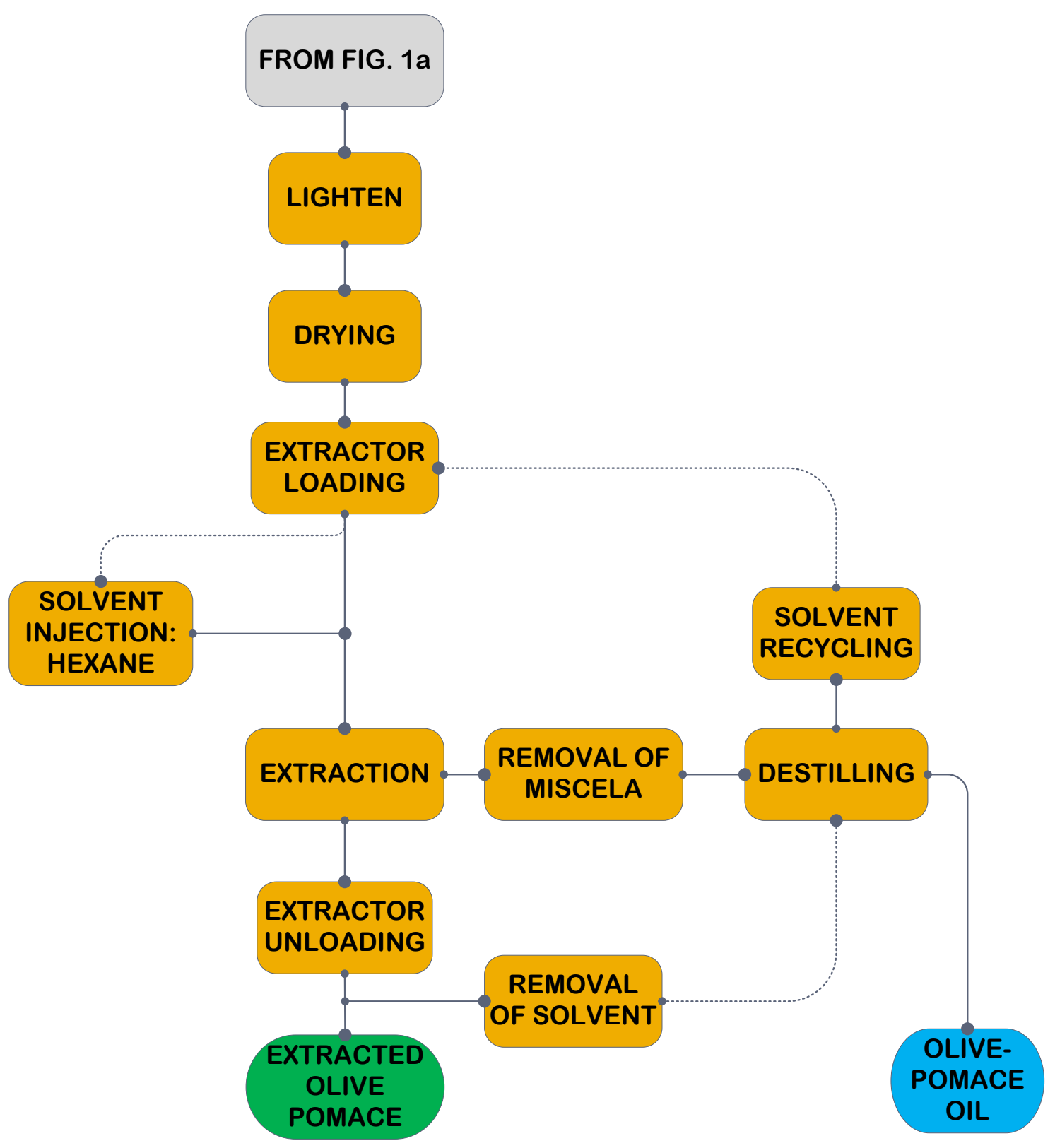

Fig. 1b. Olive oil production flowchart: olive pomace extractor (mass transfer method). 


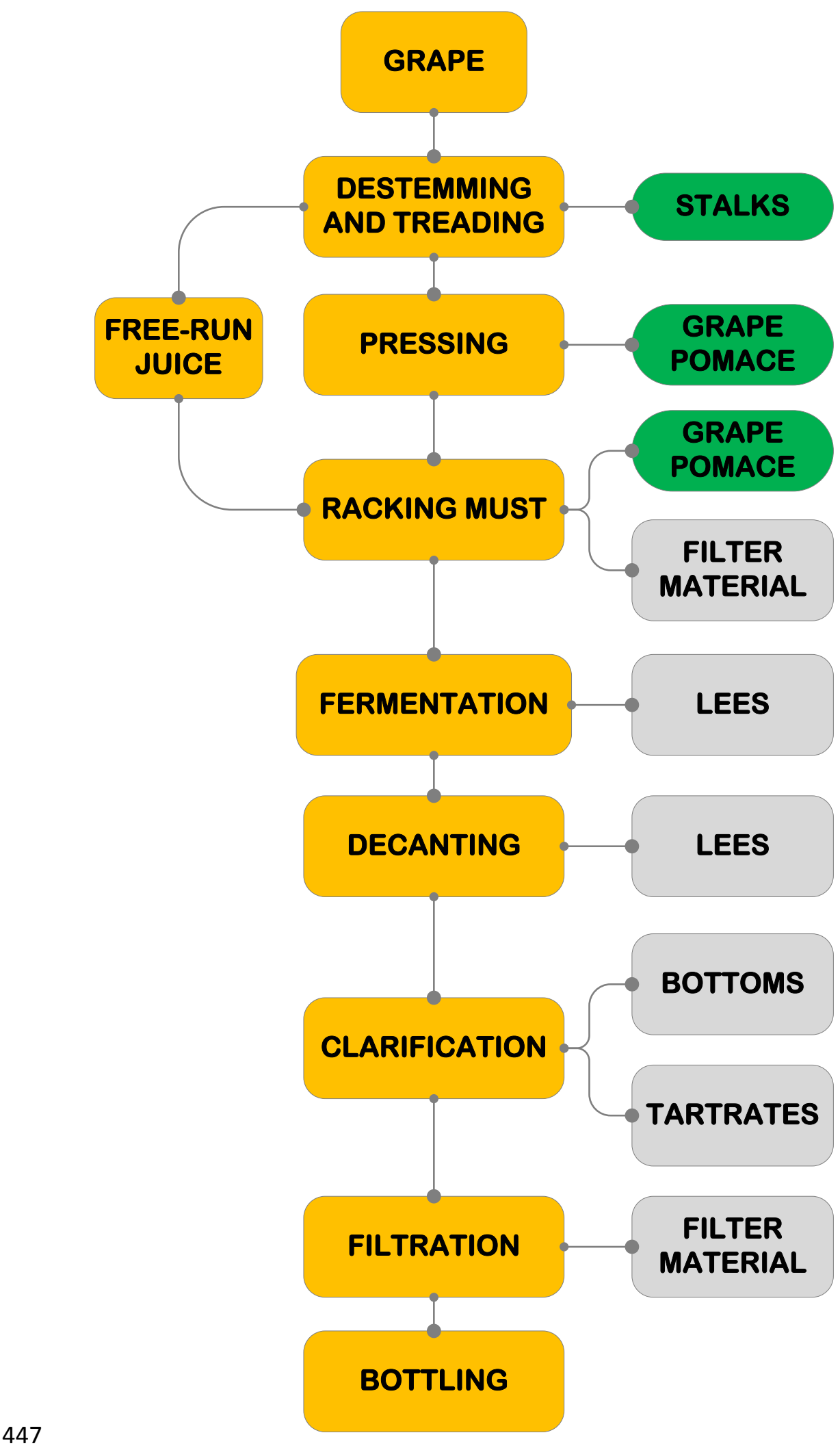

Fig. 2. White wine production flowchart. 


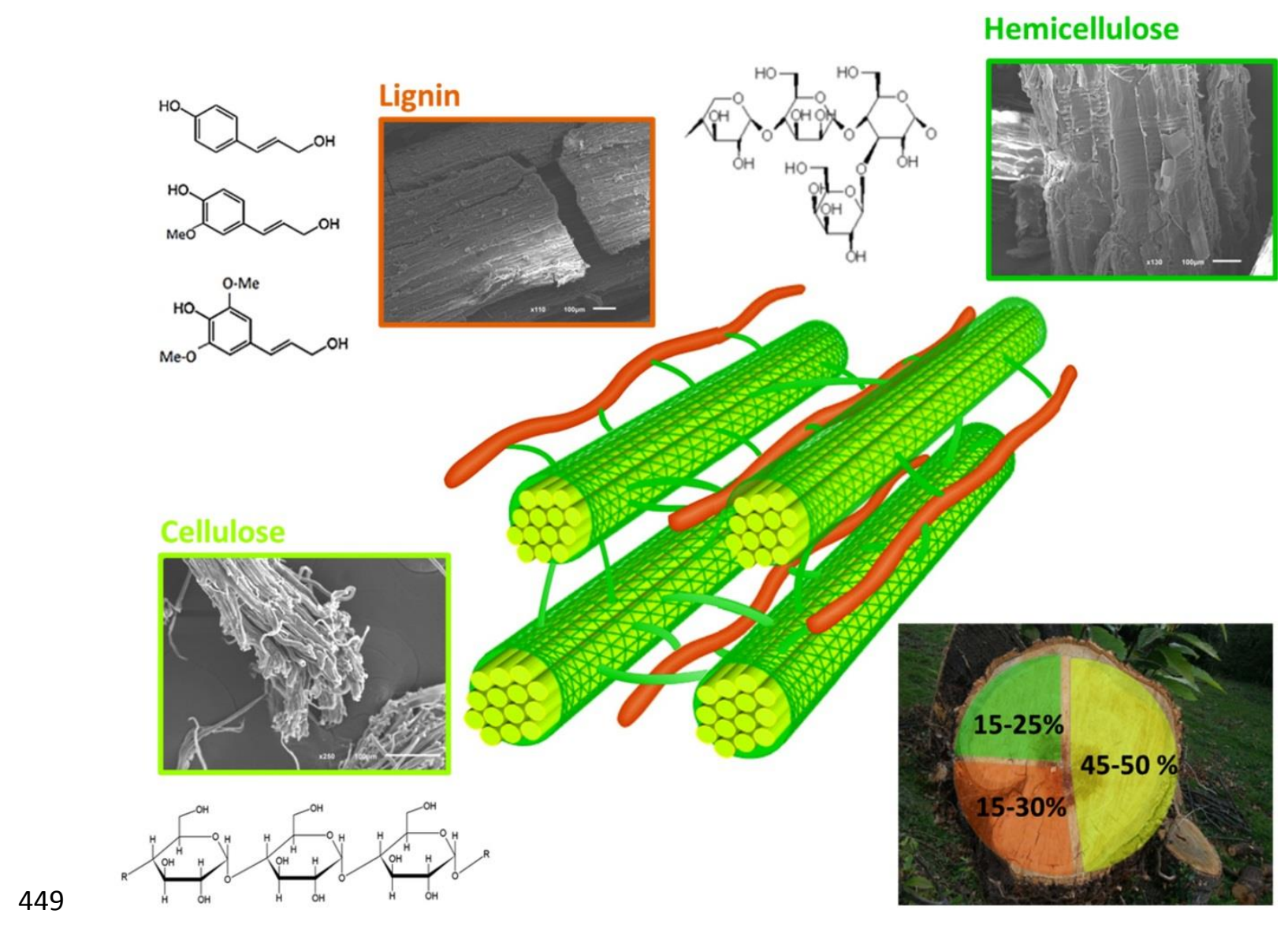

Fig. 3. 3D biomass structure 


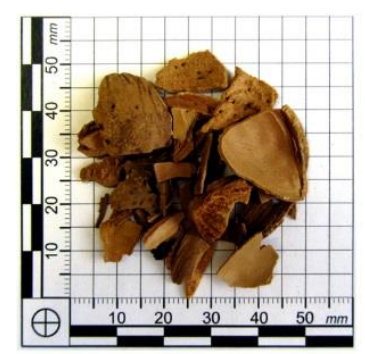

Almond shell

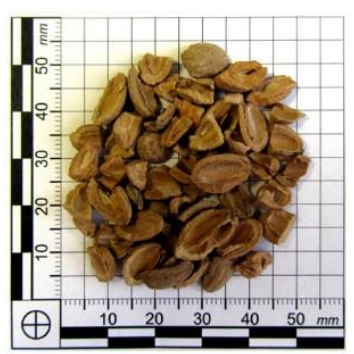

Dried oil-mill stone

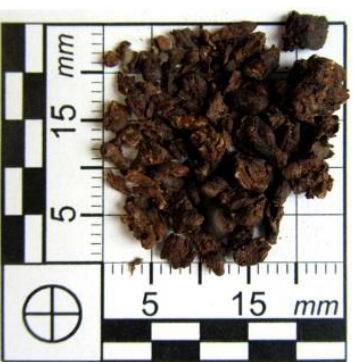

Grape pomace

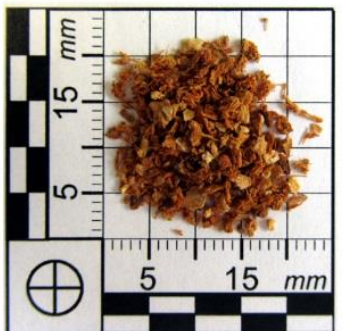

Horse chestnut burr

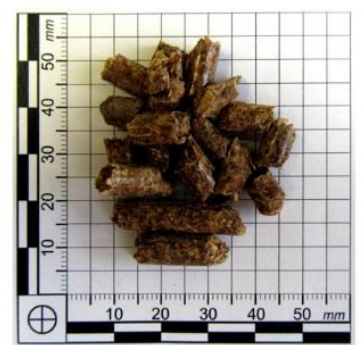

Olive tree pruning pellets

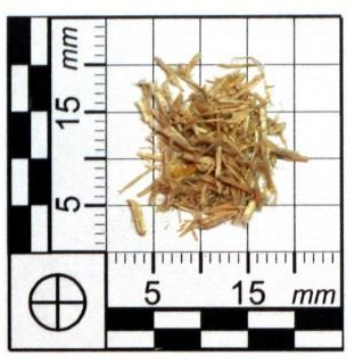

Cherry-tree chips

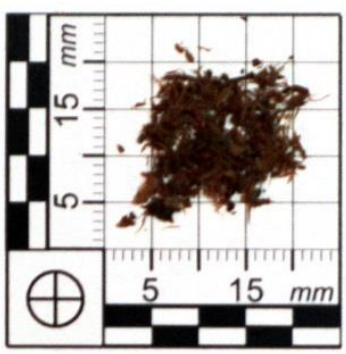

Eucalyptus bark

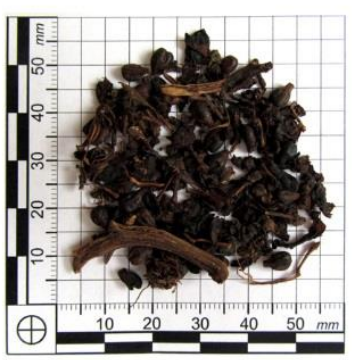

Grape seed flour

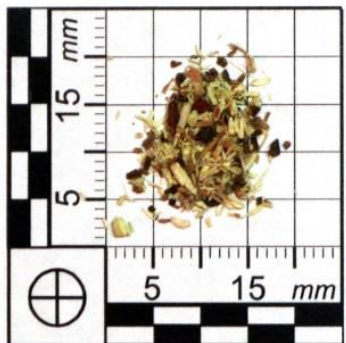

Mimosa branches

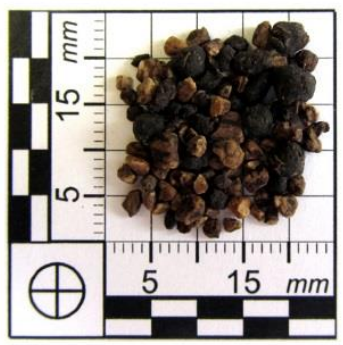

Olive-pomace

oil-extractor

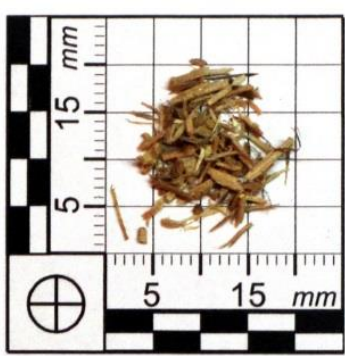

Chestnut tree chips

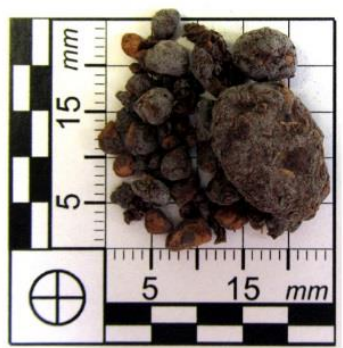

Extracted olive

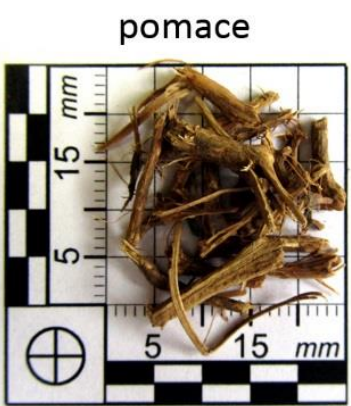

Grape stalk

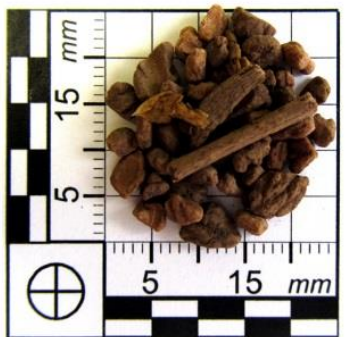

Olive-mill stone (ar)

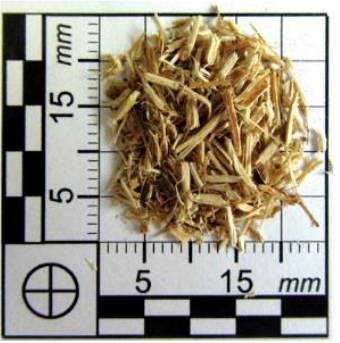

Poplar branches

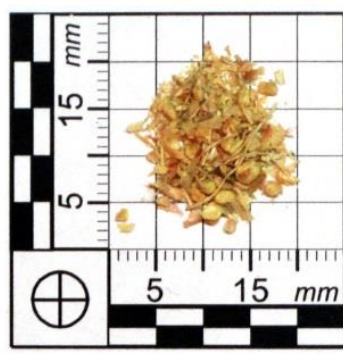

Corncob

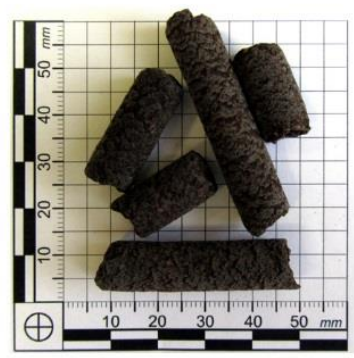

Extracted olive pomace pellets

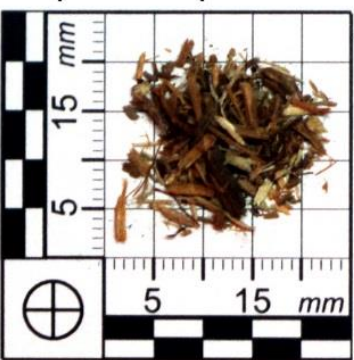

Hazelnut + alder chips

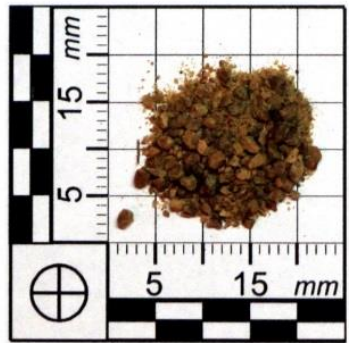

Olive stone

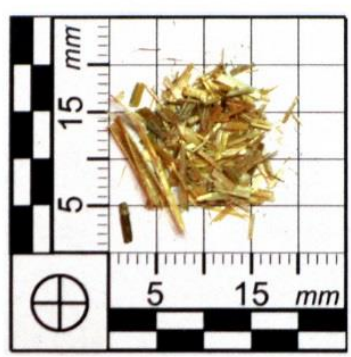

Wheat straw

Fig. 4. Pictures of the samples analysed. 


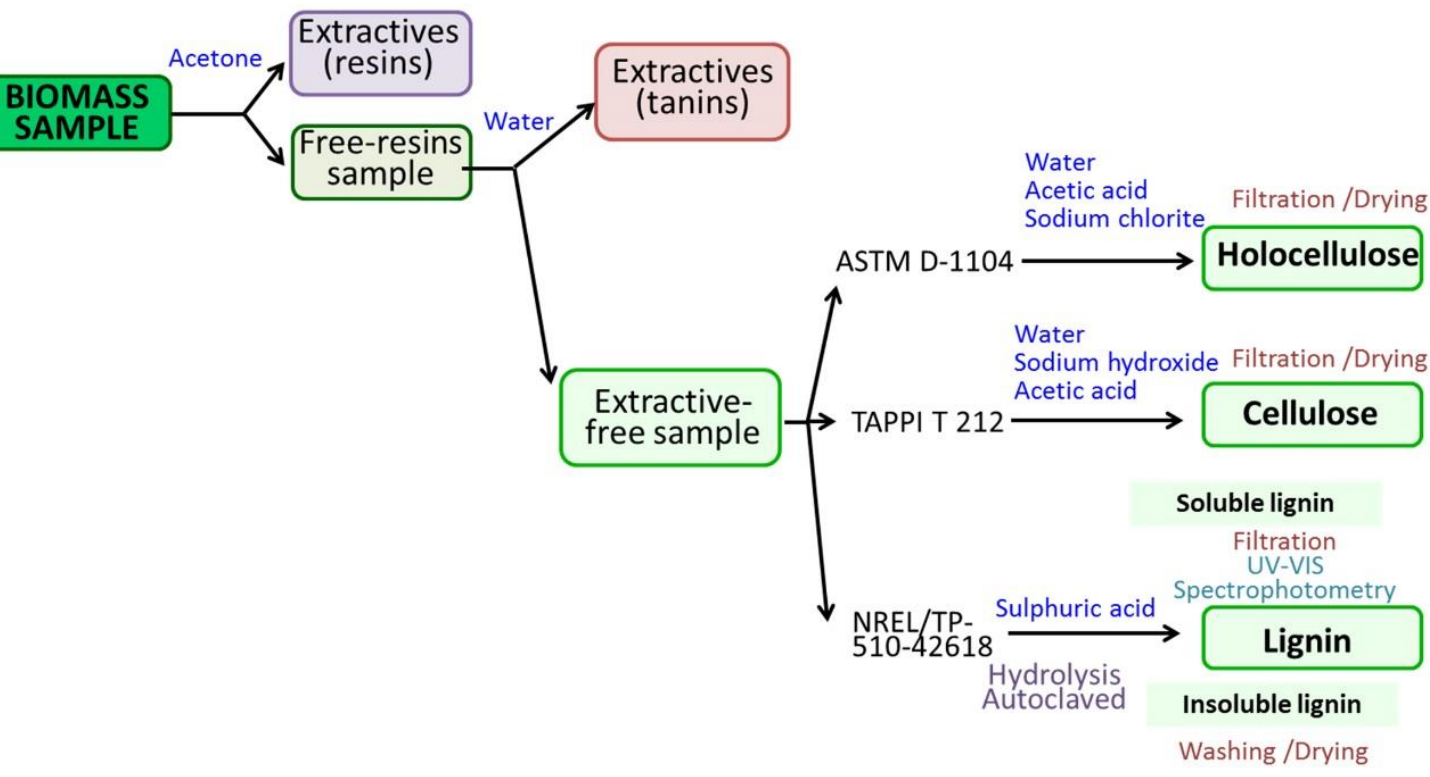

Fig. 5. Experimental procedure chart. 


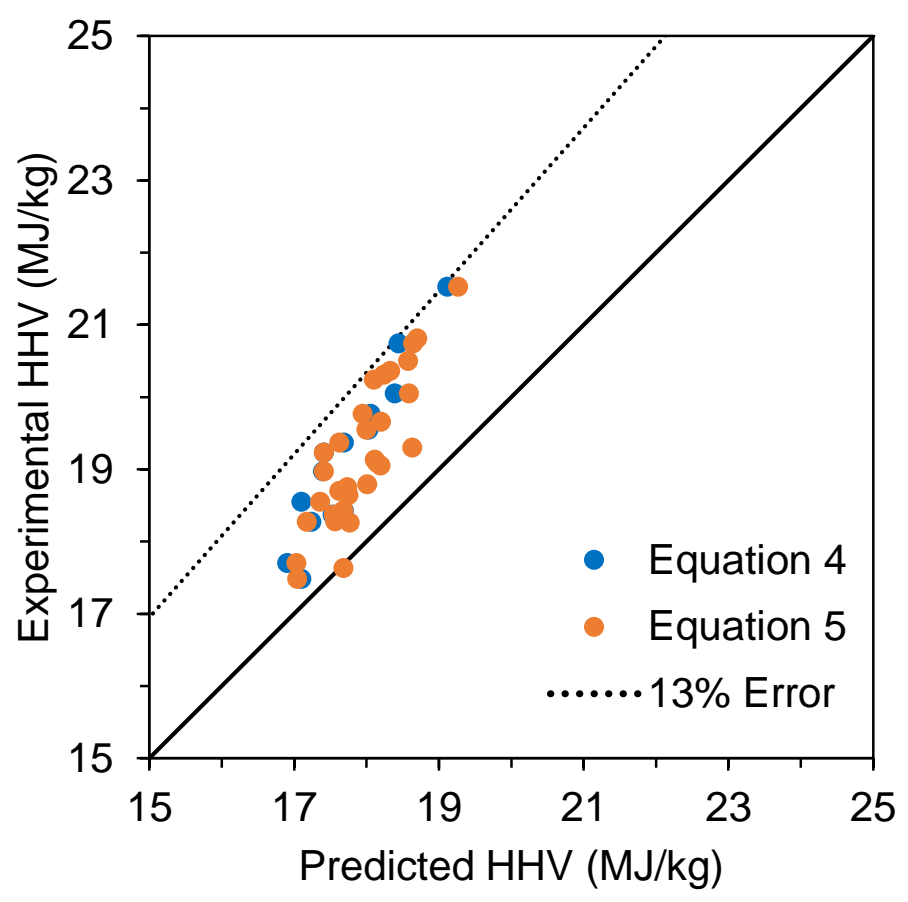

455

Fig. 6. Predicted vs. experimental HHV from data in the bibliography. 
457 Table 1. Available potential biomass (t/year) and average production cost (€/t)

458 in Spain (IDAE, 2007)

\begin{tabular}{|c|c|c|c|c|}
\hline \multicolumn{2}{|l|}{ Origin } & \multirow{2}{*}{$\begin{array}{l}\begin{array}{l}\text { Biomass } \\
\text { (t/year) }\end{array} \\
2984243\end{array}$} & \multirow{2}{*}{$\begin{array}{l}\begin{array}{l}\text { Biomass } \\
\text { (tep/year) }\end{array} \\
636273\end{array}$} & $\begin{array}{l}\text { Average } \\
\text { costs }(€ / t)\end{array}$ \\
\hline Existing forest & $\begin{array}{l}\text { Wood harvesting } \\
\text { remains }\end{array}$ & & & 25.59 \\
\hline areas & $\begin{array}{l}\text { Whole tree } \\
\text { harvesting }\end{array}$ & 15731116 & 3414158 & 43.16 \\
\hline $\begin{array}{l}\text { Agricultural } \\
\text { residues }\end{array}$ & $\begin{array}{l}\text { Herbaceous } \\
\text { Woody }\end{array}$ & $\begin{array}{l}14434566 \\
16118220\end{array}$ & 6392631 & 20.97 \\
\hline \multicolumn{2}{|c|}{$\begin{array}{l}\text { Herbaceous biomass susceptible to } \\
\text { implementation in agricultural land }\end{array}$} & 14737868 & 3593148 & 53.39 \\
\hline \multicolumn{2}{|c|}{$\begin{array}{l}\text { Woody biomass susceptible to } \\
\text { implementation in agricultural land }\end{array}$} & 6598861 & 1468173 & 36.26 \\
\hline \multicolumn{2}{|c|}{$\begin{array}{l}\text { Woody biomass susceptible to } \\
\text { implementation in forest land }\end{array}$} & 15072320 & 1782467 & 42.14 \\
\hline \multicolumn{2}{|c|}{ Total potential biomass in Spain } & 88677193 & 17286851 & \\
\hline
\end{tabular}

459 
Table 2. Structural composition-based models (Callejón-Ferre et al., 2014).

\section{AUTHOR \\ CORRELATION (HHV, MJ/kg dry basis)}

S\&D (Shafizadeh et al., 1976)

TIL (Tillman, 2012)

WHI (White, 1987)

$\mathrm{HHV}=0.17389[\mathrm{Ce}]+0.26629[\mathrm{~L}]+0.32187[\mathrm{E}]$ $\mathrm{HHV}=0.17389[\mathrm{Ce}]+0.26629\left(100-\left[\mathrm{Ce}^{\star}\right]\right)$ $\mathrm{HHV}=17.9017+0.07444\left[\mathrm{~L}^{\star}\right]+0.0661\left[\mathrm{E}^{\star}\right]^{\mathrm{a}}$

$$
\begin{aligned}
& H H V=17.6132+0.0853\left[L^{*}\right]^{a} \\
& H H V=17.4458+0.0907\left[L^{*}\right]^{a} \\
& H H V=18.0831+0.0637\left[L^{*}\right]^{a} \\
& H H V=17.7481+0.0800\left[L^{*}\right](100-[E]) / 100+0.0886[E]^{a}
\end{aligned}
$$

J\&G (Jiménez and González, $\quad H H V=(1-[$ Ash $] /([\mathrm{Ce}]+[\mathrm{L}]+[\mathrm{E}]))(0.17389[\mathrm{Ce}]+$ 1991)

DEM01 (Demirbaş, 2001)

$$
0.26629[\mathrm{~L}]+0.32187[\mathrm{E}])
$$

$\mathrm{HHV}^{* *}=0.0889\left[\mathrm{~L}^{* *}\right]+16.8218$

$\mathrm{HHV}^{* *}=0.0893\left[\mathrm{~L}^{* *}\right]+16.9742$

$\mathrm{HHV}^{* *}=0.0877\left[\mathrm{~L}^{* \star}\right]+16.4951$

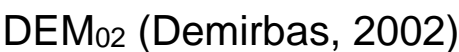

DEM03 (DEMIRBAŞ, 2003)

DEM04 (Demirbas, 2004)

$$
\begin{aligned}
& \Delta H H V=0.00639[E] 2+0.223[E]+0.691 \\
& H_{H V}^{* *}=0.0864\left[L^{* *}\right]+16.6922 \\
& \Delta H H V=0.383[E]-0.0387
\end{aligned}
$$

ACA (Acar and Ayanoglu,

$$
H H V=0.0979[L]+16.292
$$

\section{COMMENTS}

Lignocellulosic biomass.

Woody biomass.

Not extracted wood. Neither $\mathrm{R}^{2}$ ajust, not SE available

Extractive free wood. Neither $\mathrm{R}^{2}$ ajust, not SE available

Extractive free softwood. Neither

$\mathrm{R}^{2}$ ajust, not $\mathrm{SE}$ available

Extractive free hardwood. Neither

$\mathrm{R}^{2}$ ajust, not SE available

Not extracted wood. Neither $\mathrm{R}^{2}$ ajust, not

SE available

Vegetal biomass. Neither $\mathrm{R}^{2}$ ajust, not

SE available

Vegetal biomass. SE not available Wood and bark. SE not available Not woody vegetal biomass. SE not available

Vegetal biomass. SE not available. Bark and shell. SE not available Vegetal biomass. Neither $\mathrm{R}^{2}$ ajust, not SE available

Vegetal biomass. SE not available

\section{Ce: cellulose + hemicellulose; L: lignin; E: extractive both measured in dry basis percentage}

* Indicates composition (\%) in dry and extractive free basis.

** Indicates composition (\%) in dry ash free and extractive free basis.

Not SE: not standard error available.

a These correlations can be converted to $\mathrm{MJ} / \mathrm{kg}$ as: $1 \mathrm{Btu} / \mathrm{lb}=2,3261 \times 10^{-3} \mathrm{MJ} / \mathrm{kg}$. 
462 Table 3. HHV data used in this article (García et al., 2014a) and (García et al., 463 2014b).

\begin{tabular}{ll}
\hline Sample & HHV (kJ/kg) \\
\hline Almond shell & 18.275 \\
Cherry-tree chips & 17.595 \\
Chestnut tree chips & 17.485 \\
Corncob & 17.344 \\
Dried oil mill stone & 18.092 \\
Eucalyptus bark & 17.752 \\
Extracted olive pomace & 18.186 \\
Extracted olive pomace pellets & 18.182 \\
Grape pomace & 17.019 \\
Grape seed flour & 16.467 \\
Grape stalk & 18.809 \\
Hazelnut +alder chips & 17.555 \\
Horse chestnut burr & 17.165 \\
Mimosa branches & 16.237 \\
Oil-mill stone (ar) & 16.484 \\
Olive stone & 17.884 \\
Olive tree pruning pellets & 18.720 \\
Olive-pomace oil-extractor & 18.687 \\
Poplar branches & 18.411 \\
Wheat straw & 17.692 \\
\hline
\end{tabular}


465 Table 4. Chemical composition of biomass samples obtained by chemical 466 extraction.

\begin{tabular}{|c|c|c|c|c|c|c|}
\hline Sample & $E^{a}$ & HoloC $^{b}$ & $\mathbf{C}^{b}$ & HemiC $^{b}$ & I.L.' & S.L. ${ }^{b}$ \\
\hline Almond shell & 8.02 & 69.12 & 55.07 & 14.05 & 28.37 & 2.51 \\
\hline Cherry-tree chips & 1.88 & 75.64 & 46.51 & 29.13 & 22.13 & 2.23 \\
\hline Chestnut tree chips & 0.35 & 72.61 & 43.39 & 29.22 & 24.74 & 2.65 \\
\hline Corncob & 8.72 & 72.50 & 29.71 & 42.79 & 24.49 & 3.02 \\
\hline Dried oil mill stone & 2.30 & 72.61 & 50.31 & 22.30 & 25.79 & 1.61 \\
\hline Eucalyptus bark & 11.30 & 65.73 & 37.31 & 28.42 & 32.37 & 1.90 \\
\hline Extracted olive pomace & 67.79 & 57.27 & 27.60 & 29.67 & 38.89 & 3.84 \\
\hline $\begin{array}{l}\text { Extracted olive pomace } \\
\text { pellets }\end{array}$ & 55.96 & 62.58 & 31.05 & 31.53 & 34.25 & 3.17 \\
\hline Grape pomace & 26.06 & 46.76 & 28.83 & 17.93 & 51.74 & 1.50 \\
\hline Grape seed flour & 9.82 & 53.55 & 37.75 & 15.80 & 45.54 & 0.91 \\
\hline Grape stalk & 39.34 & 46.37 & 43.97 & 2.40 & 51.80 & 1.83 \\
\hline Hazelnut +alder chips & 12.30 & 65.84 & 34.77 & 31.08 & 31.92 & 2.23 \\
\hline Horse chestnut burr & 43.66 & 62.85 & 44.82 & 18.03 & 36.05 & 1.11 \\
\hline Mimosa branches & 16.81 & 68.68 & 40.18 & 28.51 & 29.76 & 1.56 \\
\hline Oil-mill stone (ar) & 7.99 & 71.96 & 44.72 & 27.24 & 26.51 & 1.53 \\
\hline Olive stone & 2.98 & 69.61 & 58.93 & 10.68 & 28.64 & 1.75 \\
\hline $\begin{array}{l}\text { Olive tree pruning } \\
\text { pellets }\end{array}$ & 13.51 & 71.47 & 59.05 & 12.42 & 27.55 & 0.98 \\
\hline $\begin{array}{l}\text { Olive-pomace oil- } \\
\text { extractor }\end{array}$ & 36.84 & 68.24 & 38.20 & 30.04 & 29.31 & 2.45 \\
\hline Poplar branches & 8.02 & 72.97 & 46.16 & 26.81 & 25.63 & 1.40 \\
\hline Wheat straw & 25.70 & 75.73 & 38.56 & 37.17 & 21.71 & 2.56 \\
\hline
\end{tabular}


467 Table 5. $P$ and $R$ coefficients matrix (chemical extraction and TG).

\begin{tabular}{cccc}
\hline \multicolumn{4}{c}{ R matrix } \\
HHV & Lignin & Hemicellulose & Cellulose \\
1.0000 & 0.8291 & -0.6686 & 0.0740 \\
\multicolumn{4}{c}{ P matrix } \\
HHV & Lignin & Hemicellulose & Cellulose \\
1.0000 & 0.0009 & 0.0175 & 0.8191 \\
\hline
\end{tabular}

468 
469 Table 6. Equations based on chemical composition.

\begin{tabular}{lllll}
\hline & Equation & AAE $(\%)$ & ABE (\%) & AAD \\
\hline 4 & $\mathrm{HHV}=17.0704+0.0449 \cdot \mathrm{L}-0.0202 \cdot \mathrm{H}$ & 0.87 & 0.02 & 0.15 \\
5 & $\mathrm{HHV}=16.1964+0.0555 \cdot \mathrm{L}$ & 1.13 & 0.02 & 0.20 \\
\hline
\end{tabular}

$\mathrm{L}$ : lignin; $\mathrm{H}$ : hemicellulose (measured in mass percentage in dry ash and extractives free basis); HHV: higher heating value (MJ/kg in dry basis). 